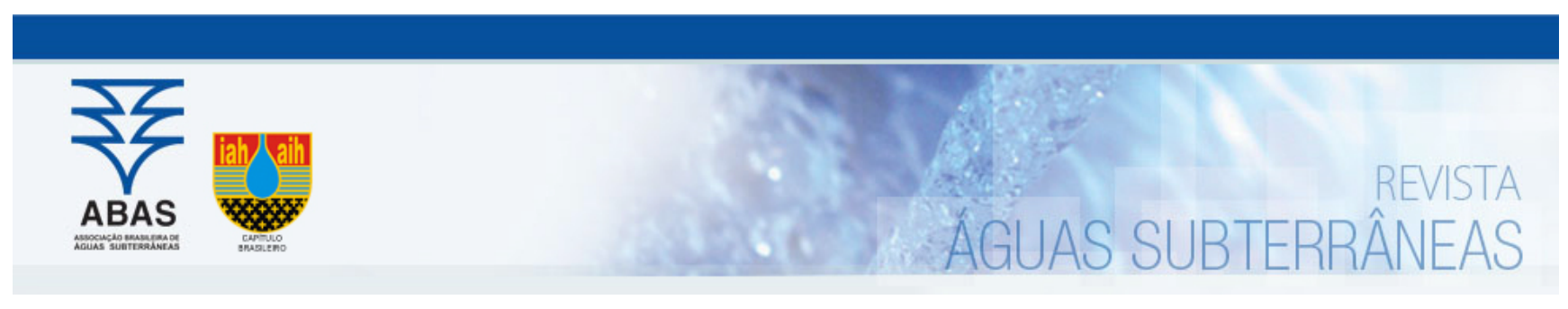

Artigos

\title{
Proteção ambiental de nascentes e afloramentos de água subterrânea no Brasil: histórico e lacunas técnicas atuais
}

\section{Environmental protection of springs and groundwater outcrops in Brazil: history and current technical gaps}

\author{
Kleber Isaac Silva de Souza1,2; Pedro Luiz Borges Chaffe3; Cátia Regina Silva de Carvalho Pinto4; Tadeu Maia Portela \\ Nogueira2 ${ }^{\bowtie}$
}

1 Instituto Brasileiro do Meio Ambiente e dos Recursos Naturais Renováveis (IBAMA), Florianópolis, Santa Catarina, Brasil.

2 Programa de Pós-Graduação em Engenharia Ambiental, Universidade Federal de Santa Catarina (UFSC), Florianópolis, Santa Catarina, Brasil.

3 Departamento de Engenharia Sanitária e Ambiental, Universidade Federal de Santa Catarina (UFSC), Florianópolis, Santa Catarina, Brasil.

4 Departamento de Engenharias de Mobilidade, Universidade Federal de Santa Catarina (UFSC), Joinville, Santa Catarina, Brasil.

$\square$ kleber i@yahoo.com, pedro.chaffe@ufsc.br, catia.carvalho@ufsc.br, tadeumaiap.n@gmail.com

\begin{tabular}{|c|c|}
\hline & Resumo \\
\hline $\begin{array}{l}\text { Palavras-chave: } \\
\text { Área de preservação permanente. } \\
\text { Legislação brasileira. } \\
\text { Nascente. } \\
\text { Olho d'água. }\end{array}$ & $\begin{array}{l}\text { Apesar das nascentes e olhos d'água serem considerados como área de preservação permanente (APP) desde } 1965 \text {, } \\
\text { o legislador por meio da Lei no } 12.651 \text {, de } 2012 \text {, retirou a proteção ambiental dos afloramentos intermitentes. Essa } \\
\text { proteção foi restabelecida pelo Supremo Tribunal Federal em fevereiro de } 2018 \text {. O conhecimento pela comunidade } \\
\text { técnico-científica da nova interpretação jurídica fixada para o diagnóstico e proteção destas feições é fundamental } \\
\text { para a realização de estudos ambientais. Este artigo apresenta a evolução histórica da legislação de proteção ambi- } \\
\text { ental no entorno de afloramentos de águas subterrâneas no Brasil e suas lacunas técnicas atuais. Por meio de dois } \\
\text { exemplos apresenta-se as lacunas na legislação regulatória quanto à delimitação precisa de nascentes e olhos } \\
\text { d'água móveis ou sujeitos à variação sazonal de nível. Sem a definição científica clara, a delimitação precisa desta } \\
\text { modalidade de APP pode ficar comprometida. Espera-se que o tema incentive trabalhos futuros para investigação de } \\
\text { soluçōes que contribuam para o aperfeiçoamento da proteção e restauração de ecossistemas relacionados com a } \\
\text { água. }\end{array}$ \\
\hline
\end{tabular}

Keywords:

Permanent preservation area. Brazilian legislation.

Headwaters.

Groundwater outcrop.

Revisado por pares.

Recebido em: 16/11/2018.

Aprovado em: 04/02/2019.

Abstract

Even though springs and groundwater outcrops are considered to be permanent preservation area (PPA) since 1965 the legislator, through Law 12651 of 2012, removed the environmental protection of intermittent outcrops. That permanent protection status was reestablished by the Brazilian Federal Supreme Court in February 2018. The knowledge about the new legal interpretation established for the diagnosis and protection of those features by the technical-scientific community is of utmost importance for conducting environmental studies. In this paper we present the historical evolution of environmental protection in the environs of groundwater outcrops in Brazil and its current technical gaps. Two examples show the gaps in the regulatory legislation regarding the precise delimitation of mobile springs and "water eyes" subject to seasonal level variation. Without a clear scientific criteria, the precise delimitation of this modality of PPA might be compromised. It is hoped that this paper will encourage future work to investigate solutions that contribute to improving the protection and restoration of water-related ecosystems.

DOI: http:/dx.doi.org/10.14295/ras.v33i1.29254

\section{INTRODUÇÃO}

A Assembleia Geral das Nações Unidas em 2015 definiu como objetivo para o desenvolvimento sustentável (ODS) que os Estados assegurem a disponibilidade e gestão sustentáve da água e saneamento para todos, com a meta de até 2020 proteger e restaurar ecossistemas relacionados com a água, incluindo montanhas, florestas, zonas úmidas, rios, aquíferos e lagos (UN, 2015, ODS 6.6). O Brasil já havia assumido por meio da Convenção da Diversidade Biológica o compromisso internacional de criar, gerir e regulamentar as áreas protegidas para conservação da biodiversidade (UNEP, 1992). As

áreas protegidas brasileiras, denominadas sob o gênero de espaços territoriais especialmente protegidos, têm previsão constitucional e se submetem a um regime jurídico específi- 
CO (BRASIL, 1988).

Desde 1934 o Brasil possui uma legislação florestal que define em todas as propriedades públicas e privadas espaços territoriais para conservação de ecossistemas nativos, originalmente denominados como florestas protetoras (BRASIL, 1934a), as quais a partir de 1965 passaram a ser definidas como áreas de preservação permanente (APP), que abrangem a superfície e a vegetação que as cobre, com a função ambiental de preservar os recursos hídricos, a paisagem, a estabilidade geológica e a biodiversidade, facilitar o fluxo gênico de fauna e flora, proteger o solo e assegurar o bem-estar das populações humanas (BRASIL, 1965, 2012a).

A gestão das águas subterrâneas e superficiais deve ser integrada, pois são sistemas interligados que podem transmitir mutuamente eventual degradação (SOLDERA; OLIVEIRA, E. D., 2017), sendo que a existência de áreas preservadas nas cabeceiras implica maior vazão (OLIVEIRA, A. S. d. et al., 2014; JESUS; OLIVEIRA, L. S.; GAMA, 2018) e melhor qualidade à água que aflora (BARRETO; RIBEIRO; BORBA, 2010; MARMONTEL; RODRIGUES, 2015).

O conhecimento da evolução histórica das definições e dos critérios para delimitação de áreas protegidas é necessário para realização de estudos no âmbito do licenciamento ambiental e perícias forenses, pois o dano ambiental é imprescritível (LEITE, 2015), o que sempre torna necessária a análise espaço-temporal do uso da terra. A partir de 1965 a legislação brasileira considera como APP os afloramentos de água subterrânea (nascentes e olhos d'água) e seu entorno, independentemente da situação topográfica ou da perenidade da surgência, com o objetivo de proteger os locais de transição entre as águas subterrâneas e superficiais. Em 1999 foi iniciada a reforma legislativa do Código Florestal de 1965 resultando na atual Lei de proteção da vegetação nativa, conhecida como Código Florestal de 2012, cujo projeto foi o assunto mais discutido pelas casas legislativas brasileiras desde a Constituição de 1988, desde a redemocratização do país.

A nova legislação resultou em considerável retrocesso ambiental pela redução significativa de áreas protegidas (SOARES-FILHO et al., 2014; RORIZ; YANAI; FEARNSIDE, 2017; ROCHEDO et al., 2018), com destaque para o entorno de afloramentos de água subterrânea intermitentes, que deixaram de ser protegidos. Os retrocessos normativos tiveram sua constitucionalidade contestada perante o Supremo Tribunal Federal (STF), que em fevereiro de 2018 restabeleceu a proteção ambiental de nascentes e olhos d'água perenes e intermitentes (BRASIL, 2018).

Contudo, ainda persistem lacunas técnicas e regulatórias para delimitação precisa de APP no entorno de nascentes e olhos d'água, cuja regulamentação é necessária para que seja assegurada a proteção efetiva dos recursos hídricos provenientes do afloramento de aquíferos, bem como se evitar divergências em estudos ambientais. Neste sentido, o presente artigo tem por objetivo apresentar o histórico da proteção ambiental do entorno de afloramentos de água subterrânea no Brasil e as lacunas técnicas e regulatórias (normativas) atuais para delimitação desta modalidade de APP para nascentes e olhos d'água móveis e sazonais.

\section{EVOLUÇÃO NORMATIVA DOS CONCEITOS E DO ENTORNO PROTEGIDO DE NASCENTES E OLHOS D'ÁGUA}

Nascente pode ser considerada como a primeira modalidade de recurso hídrico protegido. Antes de existirem normas de natureza ambiental, os afloramentos de água subterrânea significativos que constituíam, por si só, a cabeceira do rio (caput fluminis) eram considerados como bens de uso comum do povo (BRASIL, 1934b).

As diversas formas de afloramento de água subterrânea não possuem conceitos uniformes na literatura (FELIPPE; MAGALHÃES JUNIOR, 2013) e muito menos na legislação brasileira. Considerando que o conceito legal é aquele que define a área a ser protegida, a revisão da evolução das definições normativas faz-se necessária para compreender qual o espaço territorial é efetivamente protegido, bem como identificar as lacunas técnicas e regulatórias que prejudicam a delimitação precisa da APP.

Nas ciências naturais as nascentes e os olhos d'água são considerados afloramentos naturais de água subterrânea, sinônimos de fonte (SUGUIO, 1998; IBGE, 2004). O International glossary of hydrology denomina, em língua inglesa, a nascente sob o termo spring, conceituado como o lugar onde a água emerge naturalmente da rocha ou do solo e flui pela superfície ou para um corpo hídrico superficial. Quando der origem a um rio, o afloramento também é denominado como source (WMO, 2012). Spring é considerado como a descarga de água subterrânea, seja efêmera ou contínua, na superfície do solo (POEHLS; SMITH, 2009).

Na legislação brasileira, originalmente, o Código de Águas conceitua as nascentes como "as águas que surgem naturalmente ou por indústria humana" (BRASIL, 1934b, art. 89), de forma que podem integrar duas classes: naturais ou artificiais (antropogênicas). Apesar do primeiro Código Florestal (BRASIL, 1934a) estabelecer como florestas protetoras aquelas com função de conservação do regime hídrico, não havia previsão expressa para proteção dos locais de afloramento de água subterrânea. Somente com o novo Código Florestal de 1965, já sob a designação como áreas de preservação permanente, foram protegidas as "nascentes, mesmo nos chamados 'olhos d'água', seja qual for a sua situação topográfica” (BRASIL, 1965, art. 2, alínea “c”, redação original), conforme apresentado na Figura 1 a.

Cabe observar que o Código Florestal de 1965 não definiu conceitos legais para nascentes e olhos d'água, bem como não estabeleceu a largura da faixa de proteção, criando lacunas normativas que prejudicavam a efetivação destes espaços protegidos. Em 1981 a Lei da Política Nacional do Meio Ambiente (PNMA) transformou as APP em reservas ecológicas (BRASIL, 1981, art. 18), regulamentadas em 1985 pelo Conselho Nacional do Meio Ambiente (CONAMA), que procurou solucionar as lacunas ao definir as nascentes e olhos d'água como sinônimos e conceituá-las como o "local onde se verifica o aparecimento de água por afloramento do lençol freático" (BRASIL, 1986, art. 2º alínea “d”).

A mesma Resolução estabeleceu como reserva ecológica uma faixa mínima de proteção de 50 metros de largura, a 
contar da margem do afloramento, que deveria incorporar a bacia de drenagem contribuinte (BRASIL, 1986, art. $3^{\circ}$, alínea "b", inciso III). No mesmo ano, o Código Florestal de 1965 foi alterado pela Lei n. 7.511, de 1986, que modificou a largura da APP nas margens de rios, cujo valor mínimo passou de $5 \mathrm{~m}$ para $30 \mathrm{~m}$, aumentando a área protegida na zona de cabeceiras, principalmente para as margens dos rios efêmeros não compreendidos nas bacias contribuintes a montante de nascentes (Figura 1b).

A proteção adotada pelo CONAMA para as bacias de drenagem contribuintes a montante de afloramentos foi depois recepcionada pela Lei de proteção às nascentes (BRASIL, 1989a), que definiu a possibilidade de os regulamentos administrativos criarem um paralelogramo de cobertura florestal para proteção das zonas de cabeceiras (Figura 1c). Posteriormente, a Lei $n^{\circ} 7.803$, de 1989, modificou o Código Florestal de 1965, que passou a prever expressamente a APP no entorno de nascentes e olhos d'água num raio mínimo de 50 metros de largura (BRASIL, 1989b) e, quando necessário, exigir-se-ia, ainda, aquela área adicional correspondente à bacia de drenagem contribuinte, com fundamento na Resolução do CONAMA $n^{\circ} 4$, de 1985 , recepcionada pela Lei de proteção às nascentes (BRASIL, 1989a).

Contudo, em 19.07.2000 foi publicada a Lei do Sistema Nacional de Unidades de Conservação (SNUC) que extinguiu as reservas ecológicas (BRASIL, 2000, art. 60) e revogou tacitamente a Resolução do CONAMA $n^{\circ} 4$, de 1985 , por incompatibilidade. Consequentemente, o entorno protegido de nascentes deixou de incorporar a bacia de drenagem contribuinte, ficando restrito a uma faixa de 50 metros de largura (Figura 1d).

O CONAMA então editou a Resolução n ${ }^{\circ} 303$, de 2002, regulamentando o Código Florestal vigente (BRASIL, 1965) e a Lei de proteção às nascentes (BRASIL, 1989a), para restabelecer a APP “ao redor de nascente ou olho d'água, ainda que intermitente, com raio mínimo de cinquenta metros de tal forma que proteja, em cada caso, a bacia hidrográfica contribuinte" (BRASIL, 2002, art. $3^{\circ}$, inciso II), cf. Figura 1e. Pela mesma Resolução, o CONAMA novamente regulamentou o conceito de nascentes e olhos d'água, mantendo-os como sinônimos e definiu-os como o "local onde aflora naturalmente, mesmo que de forma intermitente, a água subterrânea" (BRASIL, 2002, art. $2^{\circ}$, inciso II).

A água subterrânea é aquela que ocorre no subsolo (BRASIL, 2008), mais precisamente na zona de saturação (SUGUIO, 1998; ISO, 2011), sendo sinônimo de água freática, que tem por característica ser livre e não confinada (SUGUIO, 1998). Apesar do tratamento dado às nascentes e aos olhos d'água como sinônimos na literatura técnica e na legislação ambiental regulamentar, o Código Florestal de 2012 modificou os conceitos legais destas feições, diferenciando-as, bem como alterou o regime de proteção do entorno. Para o Código Florestal de 2012 todo afloramento natural de água subterrânea (freática) constitui um olho d'água ou uma nascente. A diferença fundamental entre eles é que as nascentes são perenes e sempre dão início a um curso d'água, enquanto que os olhos d'água podem ser intermitentes e deles não derivam rios (BRASIL, 2012a).

Quanto à proteção do entorno, o Código Florestal de 2012 em sua redação original estabelecia APP para nascentes e olhos d'água perenes e intermitentes. Porém, na mesma data em que foi publicada, a Lei $n^{\circ} 12.651$, de 2012, foi alterada pela Medida Provisória $n^{\circ} 571$, de 2012, posteriormente convertida na Lei $n^{\circ} 12.727$, de 2012 , que extinguiu a APP no entorno de olhos d'água intermitentes e nas margens de cursos d'água efêmeros (BRASIL, 2012b,c), cf. Figura $1 f$.

A diferenciação dos conceitos legais entre nascentes e olhos d'água teve por objetivo extinguir a proteção ambiental do entorno de afloramentos intermitentes de água subterrânea, pois o Código Florestal de 2012 alterado pela Lei $n^{\circ} 12.727$, de 2012, somente protegia afloramentos perenes. Tal fato gerou uma nova lacuna técnica: ausência de critérios para definição da perenidade dos afloramentos.

Contudo, em 28.02.2018 o Supremo Tribunal Federal (STF) no julgamento da Ação Direta de Inconstitucionalidade (ADI) $n^{\circ} 4903$ fixou interpretação conforme a Constituição para declarar que "os entornos das nascentes e dos olhos d'água intermitentes configuram área de preservação ambiental" (BRASIL, 2018), resolvendo a referida lacuna.

A decisão do STF tem eficácia imediata e vinculante. O Poder Legislativo foi comunicado da decisão e pode alterar o Código Florestal de 2012 para deixar a redação de acordo com a interpretação fixada no controle de constitucionalidade. É uma medida facultativa e, no momento, não há qualquer previsão de que seja realizada.

Então, quando da realização de diagnósticos ambientais, os profissionais ao efetuarem a leitura do Código Florestal de 2012 devem considerar que os conceitos dos afloramentos de água subterrânea não estão atualizados e voltaram a incorporar, para fins legais, as nascentes e olhos d'água intermitentes, bem como a proteção ambiental voltou a abranger qualquer forma de exfiltração natural. Portanto, atualmente, a legislação brasileira protege o entorno de qualquer afloramento de água subterrânea, seja perene ou intermitente.

Mesmo após a evolução do complexo sistema jurídico ambiental descrito acima, sintetizado na Figura 1, ainda persistem lacunas técnicas e normativas para delimitação precisa destes espaços territoriais especialmente protegidos, que são abordadas adiante. 
Figura 1 - Evolução histórica da proteção ambiental no entorno de afloramentos de água subterrânea no Brasil

AREAS DE PRESERVAÇÃO PERMANENTE:

Evolução histórica do entorno de afloramentos naturais da água subterrânea

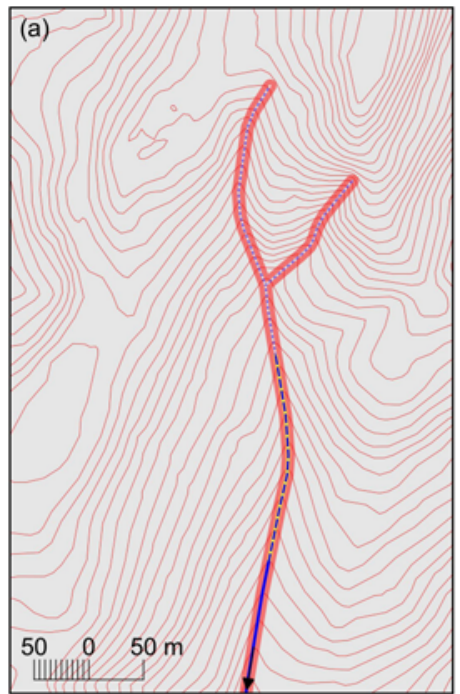

14 jan $1966-19$ jan 1986

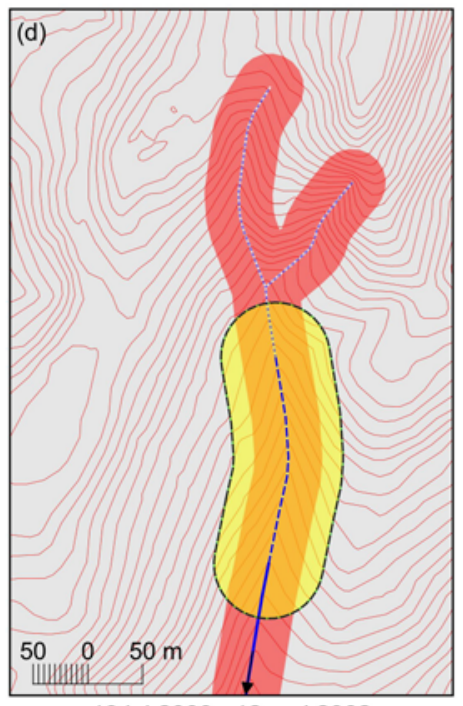

19 jul 2000 - 12 mai 2002

\section{LEGENDA:}

APP da nascente

Entorno de 50 metros de raio da nascente

Bacia hidrográfica contribuinte

Curvas de nível equidistantes $5 \mathrm{~m}$

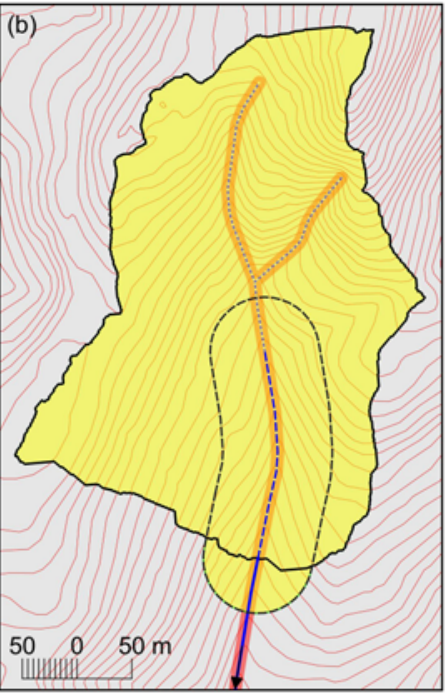

20 jan $1986-07$ jul 1986

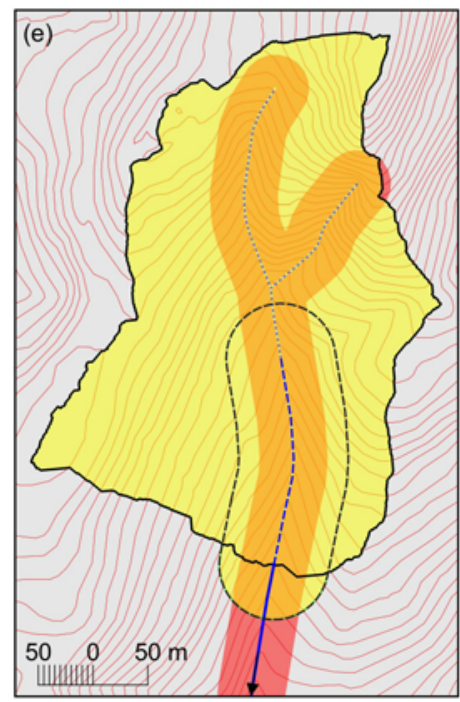

13 mai 2002 - 27 mai 2012

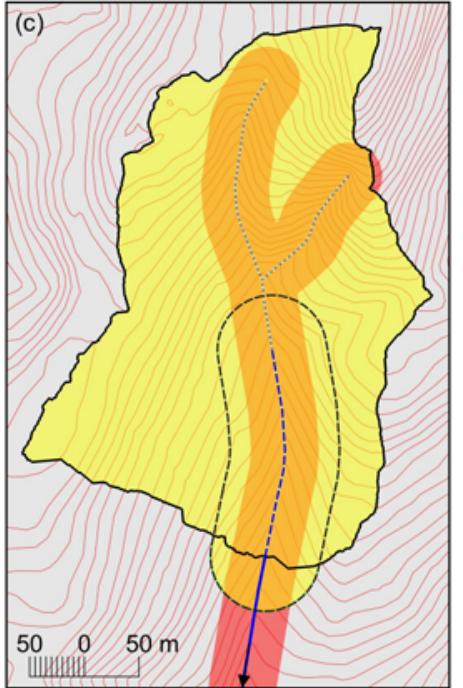

08 jul $1986-18$ jul 2000

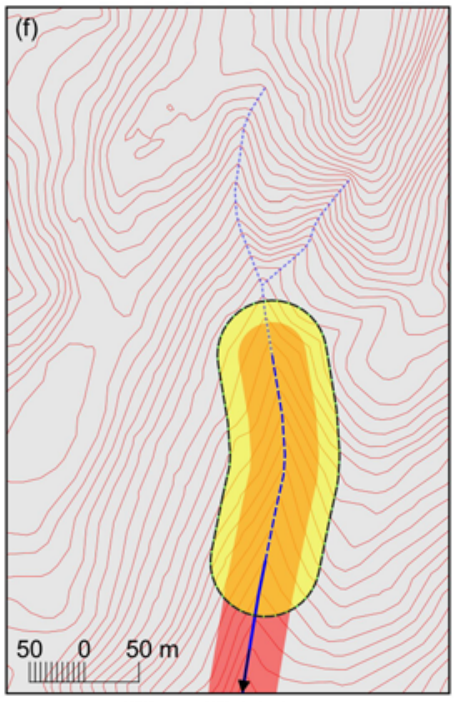

28 mai 2012 - hoje

Marcos temporais: (a)14 jan 1966: início da vigência da Lei n 4.771/1965; 19 jan 1986: data anterior à publicação da Resolução do CONAMA n 4/1985; (b) 20 jan 1986: publicação da Resolução do CONAMA n 4/1985; 07 jul 1986 data anterior à publicação da Lei $n^{\circ} 7.511 / 1986$; (c) 08 jul 1986: publicação da Lei $n^{\circ} 7.511 / 1986$; 18 jul 2000: data anterior à publicação da Lei $n^{\circ}$ 9.985/2000; (d) 19 jul 2000: publicação da Lei $n^{\circ}$ 9.985/2000; 12 mai 2002: data anterior à publicação da Resolução do CONAMA n 303/2002; (e) 13 mai 2002: publicação da Resolução do CONAMA $n^{\circ}$ 303/2002; 27 mai 2012: data anterior à publicação da Lei $n^{\circ}$ 12.651/2012 e Medida Provisória $n^{\circ}$ 571/2012; (f) 28 mai 2012: publicação da Lei $n^{\circ}$ 12.651/2012 e Medida Provisória n ${ }^{\circ}$ 571/2012 (posteriormente convertida na Lei $12.727 / 2012$ ).

Fonte: os autores (2018).

\section{DELIMITAÇÃO DO ENTORNO DE NASCENTES MÓVEIS}

Os mapeamentos de APP, quando consideram a presença de nascentes, costumam representá-las como fixas e situá-las no início dos talvegues dos cursos d'água. Entretanto, nem sempre se considera que nas zonas de cabeceiras os rios efêmeros são mais numerosos que os perenes (LEOPOLD;
MILLER, 1956), i.e., nem todos os cursos d'água iniciam em nascentes. Uma nascente ou olho d'água pode temporariamente deixar de aflorar ou até mesmo migrar de lugar, dependendo das condições do nível freático em determinado momento, que é função da pluviosidade e da recarga do aquífero não confinado (GUERRA, 1993; ISO, 2011; FELIPPE; MAGALHÃES JUNIOR, 2014). Esse comportamento dinâmico 
tem implicações para definição da extensão da faixa de proteção.

Um curso d'água perene ou intermitente pode iniciar numa nascente que se desloca no espaço. Tal fenômeno natural é bem documentado na literatura, que aponta casos de mobilidade superior a $7 \mathrm{~km}$ (FARIA, 1997 apud FELIPPE, 2013). Em pesquisa realizada por Felippe (2013), que monitorou mensalmente durante um ano hidrológico 24 nascentes no Parque Nacional da Serra do Cipó (MG) e em Lagoa Santa (MG), foi observado que 58,3\% eram móveis, com deslocamentos de até $1,6 \mathrm{~km}$.

Atualmente a definição da APP de nascente é pressuposto para a delimitação da APP de cursos d'água, pois esta última se origina após o final do seguimento efêmero, onde tem início o afloramento de água subterrânea (Figura $1 \mathrm{f}$ e Figura 2). A definição de critérios técnicos para o estabelecimento da zona de afloramento de água subterrânea é importante pelos seguintes fatos:

- Ao redor da nascente a APP geralmente é mais larga (50 metros) do que a faixa marginal de preservação do rio por ela formado (largura inicial de 30 metros);

- 0 ponto mais a montante onde ocorre o afloramento do lençol freático coincide com o início do trecho intermitente do rio, local a partir do qual as margens do curso d'água possuem APP, pois a Lei $n^{\circ} 12.727$, de 2012, extinguiu a faixa marginal de proteção ambiental dos rios efêmeros.

A área protegida de 50 metros de raio ao redor da nascente móvel não será um círculo fixo, mas uma faixa formada a partir da união das projeções destes espaços protegidos por todo o seguimento no qual ocorre a migração da nascente (Figura 2). 0 método de traçar a APP de nascentes móveis acompanhando seu deslocamento no trecho intermitente do rio já havia sido observado por Carmo, Felippe e Magalhães Junior (2014), os quais consideram que a faixa de entorno de 50 metros ao redor de nascentes móveis não parece ser a solução mais adequada para garantir a proteção desses sistemas, sendo preferível a delimitação da bacia de drenagem contribuinte.

Para fins de mapeamento de APP, deve-se considerar que o ponto mais a montante de ocorrência da nascente constitui o limite entre o trecho efêmero e intermitente do curso d'água. $\mathrm{E}$ o ponto de ocorrência mais a jusante constitui o limite entre o trecho intermitente e o perene. Contudo, existe outra lacuna importante que necessita ser pesquisada para fins de regulamentação: a definição precisa do ponto de montante a partir do qual se considera o início da APP do curso d'água e da nascente.

O Código de Águas prevê que "a nascente de uma água será determinada pelo ponto em que ela começa a correr sobre o solo e não pela veia subterrânea que a alimenta" (BRASIL, 1934b, art. 95, grifo nosso). Mas qual o tempo e escala de monitoramento devem ser utilizados para definir este local? Uma vez que a vazão e mobilidade das nascentes são sensíveis à sazonalidade da precipitação (KETCHUM; DONOVAN; AVERY, 2000), a observação durante um único ano hidrológico pode não ser suficiente para descrever com precisão o ponto de máximo da surgência. As flutuações do nível do lençol freático podem ocorrer na escala de horas até décadas (Figura 3), variando em função de eventos singulares de precipitação, mudanças climáticas e alteração do uso da terra (SNYDER, 2008).

Modelos hidrológicos podem auxiliar no estudo do comportamento da água subterrânea (ASMUTH et al., 2007; SANTAROSA; MANZIONE, 2017), inclusive para predição dos níveis freáticos críticos (LUIZ; GAIARDO; SILVA, 2018) ou reconstrução de séries temporais (JACKSON et al., 2016). Pesquisas sistemáticas com objetivo específico de definir os pontos extremos de ocorrência das nascentes móveis poderiam garantir uma regulamentação sem divergências técnicas, bem como a eficácia plena das APP instituídas para proteção dos afloramentos naturais de água subterrânea e rios intermitentes. 
Figura 2 - Perfil esquemático das três modalidades de cursos d’água previstas na Lei n 12.651 , de 2012, e da respectiva APP, com destaque para o trecho intermitente formado por nascente móvel, cujo ponto de início do afloramento (montante) constitui lacuna técnica e normativa

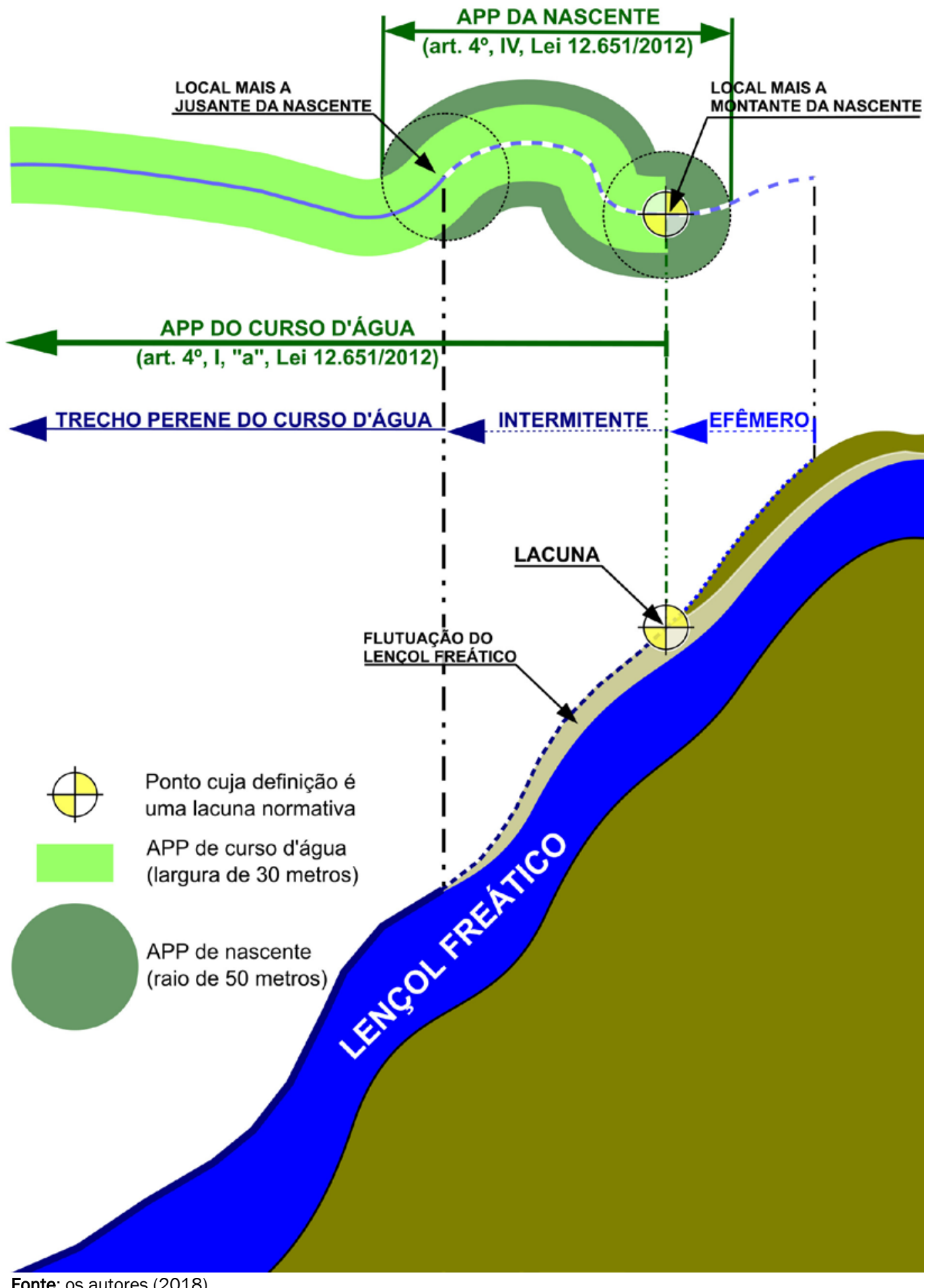

Fonte: os autores (2018)

Figura 3 - Série temporal do nível de água subterrânea informado por Jackson et al. (2016) para o poço Chilgrove House na bacia do rio Lavant, no sudeste da Inglaterra

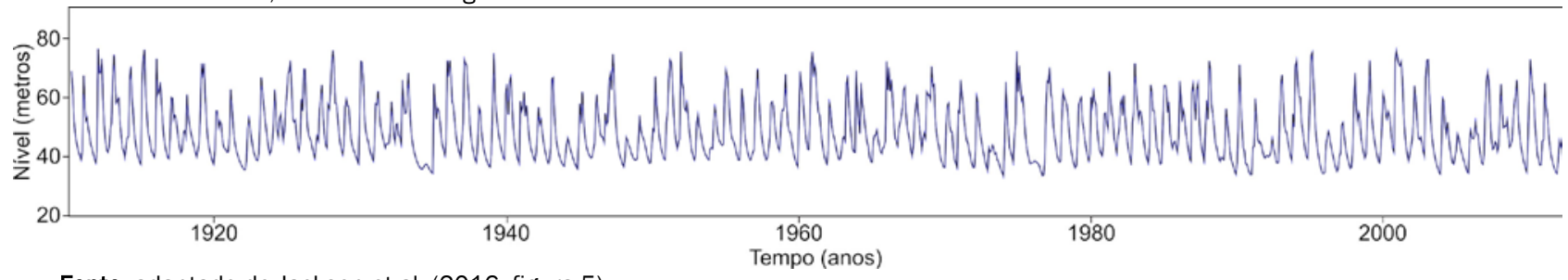

Fonte: adaptado de Jackson et al. (2016, figura 5) 


\section{DELIMITAÇÃO DO ENTORNO DE NASCENTES E OLHOS D’ÁGUA COM VARIAÇÃO SAZONAL DE NÍVEL}

Os afloramentos de água subterrânea têm suas extensões laterais sujeitas a alterações significativas em função da variação do nível do lençol freático, principalmente em locais cuja topografia apresente baixa declividade, tais como planaltos e planícies costeiras constituídas por grandes áreas úmidas. Enquanto nos rios de encostas a variação do local de exfiltração é perceptível no sentido longitudinal (montante-jusante), nas nascentes e olhos d'agua em planícies observam-se variações consideráveis em todas as direções, onde comumente as áreas de afloramento formam banhados ou locais alagados facilmente confundidos com pequenas lagoas (Figura 4).

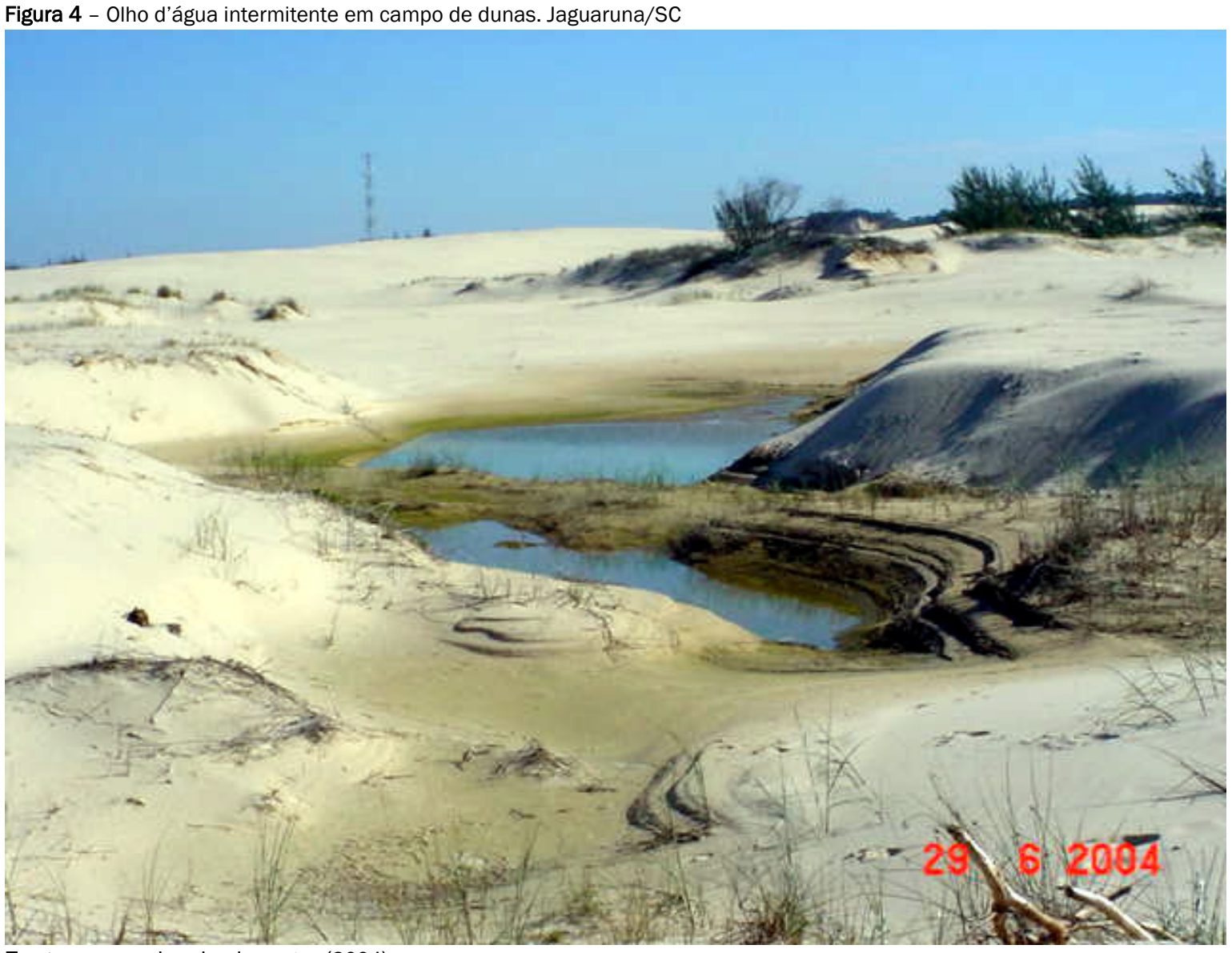

Fonte: acervo do primeiro autor (2004)

Em função do comportamento do regime de precipitações e as consequentes variações do nível do lençol freático, nos períodos de estiagem as nascentes e olhos d'água reduzem suas áreas, concentrando os afloramentos em locais de topografia mais baixa, podendo migrar no espaço ou, até mesmo, secarem em estiagens extraordinárias. Por outro lado, nos períodos chuvosos, a recarga do aquífero freático propicia a elevação do nível do lençol o que, conforme a topografia do terreno, permite a ampliação significativa da superfície hídrica da nascente ou do olho d'água.

Em planícies costeiras o lençol freático também pode apresentar variações de nível em função da oscilação da maré (WANG et al., 2012; KONG et al., 2015), o que aumenta a complexidade das variáveis envolvidas para determinação na zona costeira da sazonalidade de nascentes e olhos d'água próximos da praia (JENG et al., 2005), em estuários (MONTALTO; PARLANGE; STEENHUIS, 2007) ou de rios com influência de maré (CAROL et al., 2009).

Em monitoramentos de níveis freáticos observa-se que a oscilação do nível varia muito entre os anos hidrológicos (MANZIONE; TANIKAWA; SOLDERA, 2014; JACKSON et al., 2016), sendo necessário definir um tempo de recorrência padronizado para fins de definição do nível a ser considerado para o início da APP do afloramento.

A Figura 5 apresenta de forma esquemática os comportamentos dos afloramentos de água subterrânea em relevo plano, no qual se percebe a complexidade que envolve a delimitação das bordas de nascentes e olhos d'água. A lacuna quanto ao nível a ser considerado para o início do entorno protegido de nascentes e olhos d'água não é exclusiva para esta modalidade de APP. 0 entorno de lagos e lagoas também é afetado por lacuna análoga desde 17.09.2000, quando foi revogada a Resolução do CONAMA n 4, de 1985, que definia até aquela data o nível mais alto do reservatório como parâmetro para cálculo daquela modalidade de APP.

Em trabalho recente, Carmo, Felippe e Magalhães Junior (2014) adotaram como critério para traçar o entorno de nascente com variação sazonal de nível o perímetro médio 
da área inundada, entre o período de máxima umidade e máxima seca. Contudo, no caso de afloramentos com grande variação de nível a adoção deste critério (perímetro médio) pode fazer com que parcela considerável do entorno de 50 metros de APP fique dentro do espaço de variação sazonal, conforme se observa no olho d’água retratado no canto inferior esquerdo das Figuras $5 a, b$. Tal situação não é desejada, pois forma um ambiente de baixa resiliência ecológica (CONNELL, 1978).
Seguindo a lógica do art. 95, do Código de Águas, segundo o qual a nascente é definida pelo ponto em que ela começa a correr sobre o solo, o ideal é que eventual definição técniconormativa considere o início da APP a partir da borda do afloramento no momento de máximo sazonal, definindo-se um tempo de recorrência padrão para evitar-se divergências no caso de serem realizados monitoramentos em anos de baixa pluviosidade.

Figura 5 - Ilustração das hipóteses a serem consideradas para delimitação de área de preservação permanente (APP) no entorno de olhos d'água sujeitos à variação sazonal de nível em locais de topografia plana.

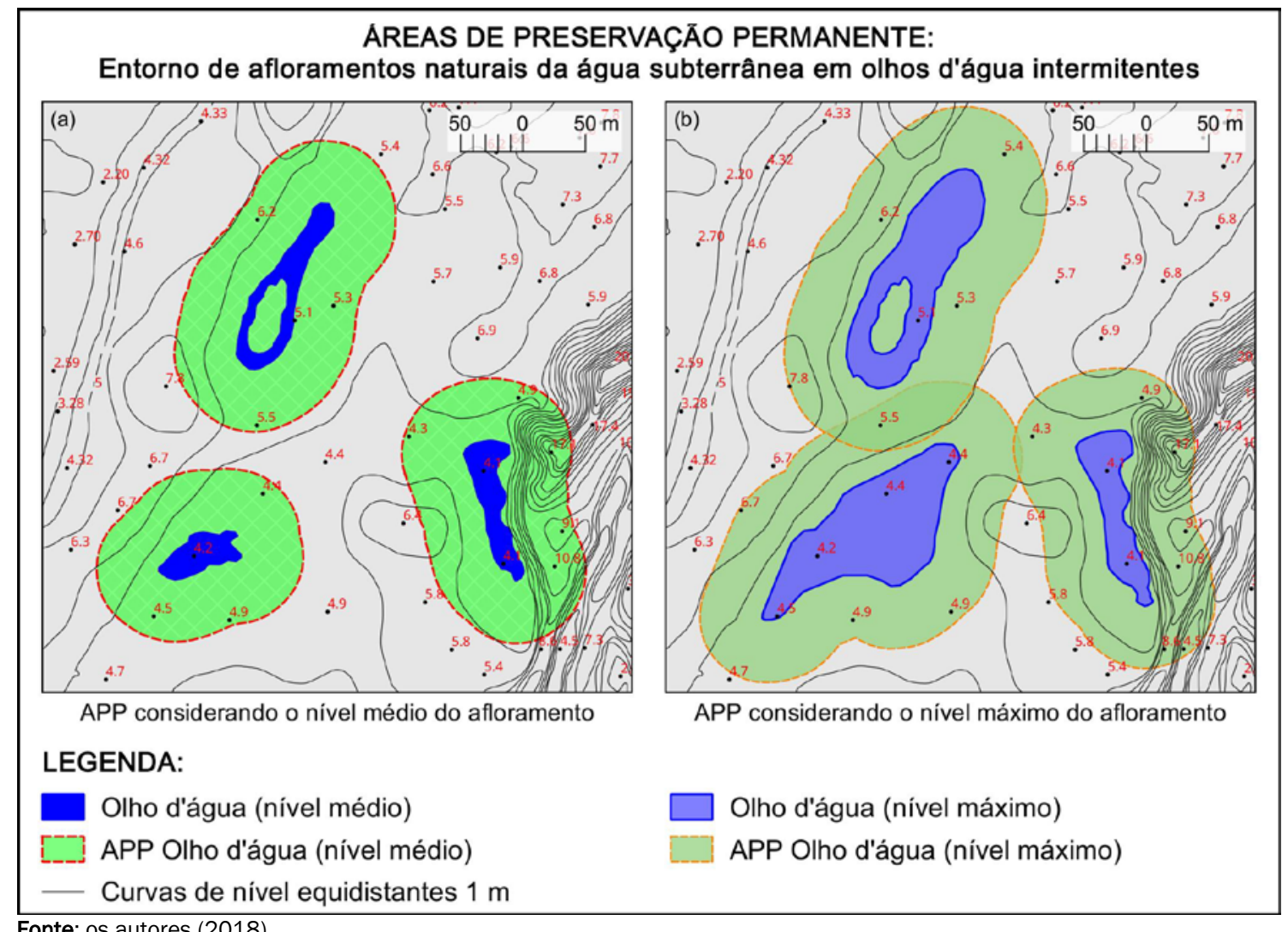

\section{CONSIDERAÇÕES FINAIS}

Apesar do Supremo Tribunal Federal (STF) ter comunicado o restabelecimento da proteção de nascentes e olhos d'água intermitentes aos Presidentes da República, do Senado e da Câmara dos Deputados, até o momento não existe projeto legislativo em tramitação para atualizar a redação dos arts. $3^{\circ}$, incisos XVII e XVIII, e $4^{\circ}$, inciso IV, da Lei $n^{\circ} 12.651$, de 2012, à interpretação fixada pelo STF na ADI nº 4903.

Na realização de diagnósticos ambientais cientistas e profissionais devem ter o cuidado de considerar a proteção de nascentes e olhos d'água intermitentes, para não serem induzidos ao erro quando da leitura do texto, ainda desatualizado, da Lei $n^{\circ}$ 12.651, de 2012. Contudo, para definição precisa desta modalidade de área de preservação permanente (APP) ainda persistem outras lacunas que necessitam de regulamentação técnica.

Enquanto para os rios existe uma rede consolidada de monitoramento dos níveis de cheias com séries históricas extensas, no caso das nascentes e olhos d'água os dados de deslocamento e variação de nível são escassos (JACKSON et al., 2016) e limitados a locais submetidos a pesquisas específicas de curta duração.

A motivação para pesquisa científica destas lacunas decorre de uma necessidade criada pela legislação ambiental atual. Uma forma de incentivar pesquisas e a produção de dados para melhor entender a dinâmica dos afloramentos naturais de água subterrânea pode ser a incorporação do monitoramento de nascentes e olhos d'água nos estudos e programas ambientais no âmbito do licenciamento ambiental de empreendimentos de significativo impacto ambiental.

Normalmente, na avaliação e controle de impactos ambientais é realizado o monitoramento da qualidade das águas superficiais e subterrâneas, de forma que é possível, sem incremento significativo de custos, incorporar aos programas ambientais o acompanhamento de mobilidade e sazonalidade dos afloramentos com a finalidade de aprimorar o conhecimento científico para posterior aperfeiçoamento da legislação regulatória ambiental. 
O ideal, ainda, é o desenvolvimento de padrões e metodologias para o monitoramento e integração dos dados produzidos (RANDRIANARIVELO; LAGARDE; HEURTEAUX, 2011) à base de dados do Sistema Nacional de Informações sobre Meio Ambiente (SINIMA), garantindo-se a compatibilidade e o compartilhamento com a Rede Integrada de Monitoramento das Águas Subterrâneas (RIMAS) do Sistema de Informações de Águas Subterrâneas (SIAGAS), mantido pelo Serviço Geológico do Brasil (CPRM).

Uma gestão sustentável que vise proteger e restaurar os ecossistemas relacionados com os recursos hídricos depende necessariamente da produção de dados e de conhecimento científico para subsidiar a política pública regulatória e de controle ambiental, com atenção especial para as APP no entorno das nascentes e olhos d'água, que constituem espaços protegidos importantes para manutenção da qualidade, disponibilidade e desempenho das funções ecossistêmicas das águas afloradas.

\section{REFERÊNCIAS}

ASMUTH, J. R. von et al. Modeling Time Series of Ground Water Head Fluctuations Subjected to Multiple Stresses. Groundwater, Wiley, v. 46, n. 1, p. 30-40, nov. 2007. DOl: 10.1111/j.1745-6584.2007.00382.x.

BARRETO, S. R.; RIBEIRO, S. A.; BORBA, M. P. (Ed.). Nascentes do Brasil: estratégias para a proteção de cabeceiras em bacias hidrográficas. São Paulo: WWF - Brasil: Imprensa Oficial do Estado de São Paulo, 2010. 140 p. il. ISBN 9788570606990.

BRASIL. Constituição da República Federativa do Brasi (1988). Diário Oficial [da] República Federativa do Brasil, Brasília, DF, 5 out. 1988. ISSN 1677-7042.

Decreto $n^{\circ} 23.793$, de 23 de janeiro de 1934. Approva o Codigo Florestal que com este baixa. Diário Oficial [da] República dos Estados Unidos do Brasil, Rio de Janeiro, RJ, 21 mar. 1934a. ISSN 1677-7042.

Decreto $n^{\circ} 24.643$, de 10 de julho de 1934. Decreta o Código de Águas. Diário Oficial [da] República dos Estados Unidos do Brasil, Rio de Janeiro, RJ, 27 jul. 1934b. ISSN 1677-7042.

Lei $n^{\circ} 12.651$, de 25 de maio de 2012. Dispõe sobre a proteção da vegetação nativa; altera as Leis $n^{\circ} 6.938$, de 31 de agosto de 1981, 9.393, de 19 de dezembro de 1996, e 11.428, de 22 de dezembro de 2006; revoga as leis $n^{\circ}$ 4.771, de 15 de setembro de 1965, e 7.754, de 14 de abri de 1989, e a Medida Provisória $n^{\circ} 2.166-67$, de 24 de agosto de 2001; e dá outras providências. Diário Oficial [da] República Federativa do Brasil, Brasília, DF, 28 mai. 2012a. ISSN 1677-7042.

Lei $n^{\circ} 12.727$, de 17 de outubro de 2012. Altera a Lei $n^{\circ} 12.651$, de 25 de maio de 2012, que dispõe sobre a proteção da vegetação nativa; altera as Leis $n^{\circ} 6.938$, de 31 de agosto de 1981, 9.393, de 19 de dezembro de 1996, e 11.428 , de 22 de dezembro de 2006; e revoga as Leis $n^{\circ}$ 4.771, de 15 de setembro de 1965, e 7.754, de 14 de abril de 1989, a Medida Provisória $n^{\circ}$ 2.166-67, de 24 de agosto de 2001, o item 22 do inciso II do art. 167 da Lei $n^{\circ} 6.015$, de 31 de dezembro de 1973 , e o $\S 2^{\circ}$ do art. $4^{\circ}$ da Lei no 12.651, de 25 de maio de 2012. Diário Oficial [da] República Federativa do Brasil, Brasília, DF, 18 out. 2012b. ISSN
1677-7042.

Lei $n^{\circ} 4.771$, de 15 de setembro de 1965. Institui o novo Código Florestal. Diário Oficial [da] República dos Estados Unidos do Brasil, Brasília, DF, 16 set. 1965. ISSN 16777042.

Lei $n^{\circ}$ 6.938, de 31 de agosto de 1981. Dispõe sobre a Política Nacional do Meio Ambiente, seus fins e mecanismos de formulação e aplicação, e dá outras providências. Diário Oficial [da] República Federativa do Brasil, Brasília, DF, 2 set. 1981. ISSN 1677-7042.

Lei $n^{\circ} 7.754$, de 14 de abril de 1989. Estabelece medidas para proteção das florestas existentes nas nascentes dos rios e dá outras providências. Diário Oficial [da] República Federativa do Brasil, Brasília, DF, 18 abr. 1989a. ISSN 1677-7042.

Lei $n^{\circ} 7.803$, de 18 de julho de 1989. Altera a redação da Lei $n^{\circ} 4.771$, de 15 de setembro de 1965, e revoga as Leis $n^{\circ} 6.535$, de 15 de junho de 1978, e 7.511, de 7 de julho de 1986. Diário Oficial [da] República Federativa do Brasil, Brasília, DF, p. 139-160, 20 jul. 1989b. ISSN 16777042.

Lei $n^{\circ} 9.985$, de 18 de julho de 2000. Regulamenta o art. 225, § $1^{\circ}$, incisos I, II, III e VII da Constituição Federal, institui o Sistema Nacional de Unidades de Conservação da Natureza e dá outras providências. Diário Oficial [da] República Federativa do Brasil, Brasília, DF, 19 jul. 2000. ISSN 1677-7042.

Medida Provisória $n^{\circ} 571$, de 25 de maio de 2012 Altera a Lei $n^{\circ}$ 12.651, de 25 de maio de 2012, que dispõe sobre a proteção da vegetação nativa; altera as Leis $\mathrm{n}^{\circ}$ 6.938 , de 31 de agosto de 1981, 9.393, de 19 de dezembro de 1996, e 11.428, de 22 de dezembro de 2006; e revoga as Leis $n^{\circ} 4.771$, de 15 de setembro de 1965, e 7.754, de 14 de abril de 1989, a Medida Provisória $n^{\circ}$ 2.166-67, de 24 de agosto de 2001. Diário Oficial [da] República Federativa do Brasil, Brasília, DF, 28 mai. 2012c. ISSN 1677-7042.

Ministério do Meio Ambiente. Conselho Nacional do Meio Ambiente (CONAMA). Resolução $n^{\circ} 303$, de 20 de março de 2002. Dispõe sobre parâmetros, definições e limites de Áreas de Preservação Permanente. Diário Oficial [da] República Federativa do Brasil, Brasília, DF, p. 68, 13 mai. 2002. ISSN 1677-7042.

Ministério do Meio Ambiente. Conselho Nacional do Meio Ambiente (CONAMA). Resolução $n^{\circ} 396$, de 3 de abril de 2008. Dispõe sobre a classificação e diretrizes ambientais para o enquadramento das águas subterrâneas e dá outras providências. Diário Oficial [da] República Federativa do Brasil, Brasília, DF, p. 64-68, 7 abr. 2008. ISSN 16777042 .

Ministério do Meio Ambiente. Conselho Nacional do Meio Ambiente (CONAMA). Resolução $n^{\circ} 4$, de de 18 de setembro de 1985. Diário Oficial [da] República Federativa do Brasil, Brasília, DF, p. 1095-1096, 20 jan. 1986. ISSN 1677-7042.

Supremo Tribunal Federal. Procurador Geral da República e outros. Ação Direta de Inconstitucionalidade $\mathrm{n}^{\circ}$ 4.903/DF. Relator: Min. Luiz Fux. Diário da Justiça Eletrônico, Brasília, DF, n. 42, p. 98, 6 mar. 2018.

CARMO, L. G. do; FELIPPE, M. F.; MAGALHÃES JUNIOR, A. P. Áreas de preservação permanente no entorno de nascentes: 
conflitos, lacunas e alternativas da legislação ambiental brasileira. Boletim Goiano de Geografia, Universidade Federal de Goiás, v. 34, n. 2, set. 2014. DOI: 10.5216/bgg.v34i2.31733.

CAROL, E. S. et al. Determination of heterogeneities in the hydraulic properties of a phreatic aquifer from tidal leve fluctuations: a case in Argentina. Hydrogeology Journal, Springer Nature, v. 17, n. 7, p. 1727-1732, maio 2009. DOI: 10.1007/s10040-009-0478-3.

CONNELL, J. H. Diversity in tropical rain forests and coral reefs. Science, American Association for the Advancement of Science (AAAS), v. 199, n. 4335, p. 1302-1310, mar. 1978. DOI: 10.1126/science.199.4335.1302.

FARIA, A. P. A dinâmica de nascentes e a influência sobre os fluxos nos canais. A água em revista, CPRM, Rio de Janeiro, v. 8, p. $74-80,1997$.

FELIPPE, M. F. Gênese e dinâmica de nascentes: Contribuições a partir da investigação hidrogeomorfológica em região tropical. 2013. 254 f. Tese (Doutorado em Geografia) - Universidade Federal de Minas Gerais, Belo Horizonte. Disponí vel em: <http://hdl.handle.net/1843/IGCC-9GQJDJ>. Acesso em: 18 jan. 2018.

FELIPPE, M. F.; MAGALHÃES JUNIOR, A. P. Conflitos conceituais sobre nascentes de cursos d'água e propostas de especialistas. Geografias, v. 9, n. 1, 2013. Disponível em: <http://igc.ufmg.br/portaldeperiodicos/index.php/geografias /article/view/583>. Acesso em: 18 abr. 2018.

Desenvolvimento de uma tipologia hidrogeomorfológica de nascentes baseada em estatística nebulosa multivariada. Revista Brasileira de Geomorfologia, v. 15, n. 3, set. 2014. DOI: $10.20502 /$ rbg.v15i3.463.

GUERRA, A. T. Dicionário geológico-geomorfológico. 8. ed. Rio de Janeiro: IBGE, 1993. 446 p. ISBN 85-240-0458-4.

INSTITUTO BRASILEIRO DE GEOGRAFIA E ESTATÍSTICA (IBGE). Vocabulário básico de recursos naturais e meio ambiente. 2. ed. Rio de Janeiro: IBGE, 2004. 332 p.

INTERNATIONAL ORGANIZATION FOR STANDARDIZATION (ISO). ISO 772:2011: Hydrometry - Vocabulary and symbols. Geneva, CH, 2011.

JACKSON, C. R. et al. Reconstruction of multi-decada groundwater level time-series using a lumped conceptual model. Hydrological Processes, Wiley, v. 30, n. 18, p. 3107 3125, abr. 2016. DOI: 10.1002/hyp.10850.

JENG, D.-S. et al. Spring-neap tide-induced beach water table fluctuations in a sloping coastal aquifer. Water Resources Research, American Geophysical Union (AGU), v. 41, n. 7, jul. 2005. DOI: 10.1029/2005wr003945.

JESUS, J. B. de; OLIVEIRA, L. S.; GAMA, D. C. Composição florística e caracterização do estado de conservação de nascentes no centro-leste da bacia hidrográfica do rio Itapicuru, semiárido da Bahia. Floresta, Universidade Federal do Paraná, v. 48, n. 2, p. 245-254, abr. 2018. DOI: 10.5380/rf.v48i2.55540.

KETCHUM, N. J.; DONOVAN, J. J.; AVERY, W. H. Recharge characteristics of a phreatic aquifer as determined by storage accumulation. Hydrogeology Journal, Springer Nature, v. 8, n. 6, p. 579-593, set. 2000. DOI: 10.1007/s100400000088.
KONG, J. et al. Effects of vadose zone on groundwater table fluctuations in unconfined aquifers. Journal of Hydrology, Elsevier BV, v. 528, p. 397-407, set. 2015 . DOI: 10.1016/j.jhydrol.2015.06.045.

LEITE, J. R. M. (Coord.). Manual de direito ambiental. São Paulo: Saraiva, 2015. 776 p.

LEOPOLD, L.; MILLER, J. Ephemeral Streams: Hydraulic Factors and Their Relation to the Drainage Net. U.S. Government Printing Office, 1956. (Geological Survey professional paper). Disponivel

em: https://pubs.er.usgs.gov/publication/pp282A. Acesso em: 21 mar. 2018.

LUIZ, T. B. P.; GAIARDO, G. F.; SILVA, J. L. S. da. Utilização de máquina de vetor de suporte para previsão de níveis de água subterrânea. Águas Subterrâneas, v. 32, n. 1, p. 25-34, jan. 2018. DOI: 10.14295/ras.v32i1.28921.

MANZIONE, R. L.; TANIKAWA, D. H.; SOLDERA, B. C. Relação entre a resposta espectral da vegetação em diferentes cultivos e níveis freáticos em área de recarga do sistema aquífero Guarani. Águas Subterrâneas, v. 28, n. 1, fev. 2014. DOI: 10.14295/ras.v28i1.27381.

MARMONTEL, C. V. F.; RODRIGUES, V. A. Parâmetros Indicativos para Qualidade da Água em Nascentes com Diferentes Coberturas de Terra e Conservação da Vegetação Ciliar. Floresta e Ambiente, FapUNIFESP (SciELO), v. 22, n. 2, p. 171-181, mai. 2015. DOI: 10.1590/2179-8087.082014.

MONTALTO, F. A.; PARLANGE, J.-Y.; STEENHUIS, T. S. A simple model for predicting water table fluctuations in a tidal marsh. Water Resources Research, American Geophysical Union (AGU), v. 43, n. 3, mar. 2007. DOI: 10.1029/2004wr003913.

OLIVEIRA, A. S. de et al. Stream flow regime of springs in the Mantiqueira Mountain Range region, Minas Gerais State. CERNE, FapUNIFESP (SciELO), v. 20, n. 3, p. 343-349, set. 2014. DOI: $10.1590 / 01047760201420031268$.

POEHLS, D.; SMITH, G. J. Encyclopedic dictionary of hydrogeology. Burlington, MA: Academic Press, 2009. 517 p. ISBN 978-0-12-558690-0.

RANDRIANARIVELO, T.; LAGARDE, P.; HEURTEAUX, V. Sensor Web Enablement Standards for Groundwater Monitoring. In: LECTURE Notes in Geoinformation and Cartography. Springer Berlin Heidelberg, out. 2011. p. 141-156. DOI: 10.1007/978-3-642-10595-1_9.

ROCHEDO, P. R. R. et al. The threat of political bargaining to climate mitigation in Brazil. Nature Climate Change, Springer Nature, jul. 2018. DOI: 10.1038/s41558-018-0213-y.

RORIZ, P. A. C.; YANAI, A. M.; FEARNSIDE, P. M. Deforestation and Carbon Loss in Southwest Amazonia: Impact of Brazil's Revised Forest Code. Environmental Management, Springer Nature, v. 60, n. 3, p. 367-382, maio 2017. DOI: 10.1007/s00267-017-0879-3.

SANTAROSA, L. V.; MANZIONE, R. L. Modelo Hidrogeológico Conceitual da Estação Ecológica de Santa Bárbara (EEcSB) em área do Sistema Aquífero Bauru (SAB). Águas Subterrâneas, v. 31, n. 4, p. 404, nov. 2017. DOI: 10.14295/ras.v31i4.28826.

SNYDER, D. T. Estimated depth to ground water and configuration of the water table in the Portland, Oregon area: U.S. 
Geological Survey Scientific Investigations Report 20085059. USGS, 2008. 40 p. Disponivel em: http://pubs.usgs.gov/sir/2008/5059/. Acesso em: 20 abr. 2018.

SOARES-FILHO, B. et al. Cracking Brazil's Forest Code. Science, American Association for the Advancement of Science (AAAS), v. 344, n. 6182 , p. $363-364$, abr. 2014. DOI: 10.1126/science.1246663.

SOLDERA, B. C.; OLIVEIRA, E. D. Água sustentável (as): um novo método para a governança da água. Águas Subterrâneas, v. 31, n. 2, p. 30, mar. 2017. DOI: 10.14295/ras.v31i2.28650.

SUGUIO, K. Dicionário de geologia sedimentar e áreas afins. Rio de Janeiro: Bertrand Brasil, 1998. 1222 p.

UN GENERAL ASSEMBLY. Transforming our world: the 2030 Agenda for Sustainable Development. 21 out. 2015. Resolu- tion A/RES/70/1. Disponivel em: <http://www.refworld.org/docid/57b6e3e44.html>. Acesso em: 10 jul. 2018.

UNITED NATIONS ENVIRONMENT PROGRAMME (UNEP). Convention on Biological Diversity. Rio de Janeiro: UNEP, 1992. Disponivel em: <https://treaties.un.org/doc/Treaties/1992/06/19920605 \%2008-44\%20PM/Ch_XXVII_08p.pdf>. Acesso em: 24 fev. 2017.

WANG, X. et al. Loading effect of water table variation and density effect on tidal head fluctuations in a coastal aquifer system. Water Resources Research, American Geophysical Union (AGU), v. 48, n. 9, set. 2012. DOI: 10.1029/2011wr011600.

WORLD METEOROLOGICAL ORGANIZATION (WMO). International glossary of hydrology. Switzerland, Geneva: WMO, 2012. 469 p. ISBN 9789263033858. 